may cause visual hallucinations, and reduction of the dose of these drugs may be needed when amantadine is prescribed.

All patients except two were taking conventional antiParkinsonian drugs and the trial established the additive value of amantadine. Its value as a single treatment for Parkinsonism is as yet undetermined (Alstead, 1970).

Our thanks are due to Dr. Allan Galbraith, of Geigy Ltd., who supplied the capsules, and to Dr. E. Lewis-Faning for the statistics. Thanks are also due to Mrs. Pearson and her team in the occupational therapy department and to Sister Stafford of the outpatient department. We would like to thank Dr. Eric Dormer, Dr. Eric Frankel, and Dr. A. A. G. Lewis, who kindly offered us patients under their care for trial; and Dr. D. Scott, of the London Hospital, for his advice. We also thank the North-east Metropolitan Regional Hospital Board for their contribution from the research fund.
ADDENDUM.-Since this paper was written two further articles have been published: K. R. Hunter, G. M. Stern, D. R. Laurence, and P. Armitage (Lancet, 1970, 1, 1127) and J. D. Parkes, K. J. Zilkha, P. Marsden, R. C. H. Baxter, and R. P. Knill-Jones (Lancet, 1970, 1, 1130). The paper by Hunter et al. confirmed our results of the limited use of amantadine in Parkinsonism.

REFERENCES

Alstead, S. (1970). Lancet, 1, 522.

Calne, D. B., Brennan, J., Spiers, A. S. D., and Stern, G. M. (1970). British Medical fournal, 1, 474.

Parkes, J. D., Zilkha, K. J., Calver, D. M., and Knill-Jones, R. P. (1970). Lancet, 1, 259.

Schwab, R. S., England, A. C., Poskanzer, D. C., and Young, R. R. (1969). Fournal of the American Medical Association, 208, 1168.

\title{
Postoperative Pulmonary Atelectasis and Collapse, and its Prophylaxis with Intravenous Bicarbonate
}

\author{
M. O'DRISCOLL, * F.R.c.s.
}

\begin{abstract}
Cummary: Of 181 patients undergoing major abdomi$\checkmark$ nal surgery 116 developed chest complications associated with a metabolic acidosis, low $\mathrm{PcO}_{2}$, depressed tidal volume, increased respiratory rate, but no increase in minute volume. In a matched group of $\mathbf{1 1 6}$ patients given intravenous bicarbonate postoperatively only 15 developed chest complications. This suggests that respiratory physiological dead space decreases in patients with pulmonary collapse and atelectasis following surgery. Acidotic resviration proved inefficient in the postoperative period, and intravenous bicarbonate had a very pronounced effect on the tidal and minute volumes of acidotic patients with pulmonary collapse and atelectasis.
\end{abstract}

\section{Introduction}

Chest complications following paramedian incisions in the abdomen, and particularly those following gastric surgery, increase mortality and morbidity in the postoperative period. Their incidence, which has not fallen as dramatically as expected with the recent improvements in anaesthesia and surgery, varies from $85.6 \%$ (Collins et al., 1968) to $34 \%$ (Palmer, 1955) and 30\% (Stringer, 1947). The causes of these complications include position alone (Prys-Roberts $t$ t al., 1967), infection (Collins et al., 1968), diaphragmatic and abdominal splinting (Nunn et al., 1965), pneumoperitoneum, decrease in pulmonary compliance (Lewis and Welch, 1965), reduction of respiratory amplitude (Ngai, 1967), and loss of periodic deep inspiration under anaesthesia (Bendixen et al., 1964). The problem is certainly multifaceted, and the answer complex.

I undertook this study after observing that patients who had a metabolic acidosis on the first postoperative day were those who developed atelectasis and lobar collapse. Therefore if it was possible to prevent this acidosis the incidence of chest complications might fall.

\section{Patients and Methods}

The study group, comprising 181 patients undergoing major abdominal surgery, was divided randomly into two groups. These were not matched for age, sex, or severity of the surgical procedure. All the patients came from the same group of wards and received identical nursing care and physiotherapy. The same surgeons, anaesthetists, and nursing teams carried out the operations, no record being made of individual variation in technique; all operations lasted at least three-quarters of an hour.

The two groups were comparable in age, sex distribution, and type of operation, analgesia, and anaesthetic technique, the only difference being that the control group (group 1) did not receive intravenous bicarbonate, whereas the other group (group 2) did (Table I).

Bicarbonate.-All the patients in group 2 received $100 \mathrm{mEq}$ of sodium bicarbonate (an $8.4 \%$ solution prepared by the pharmacological department of St. James's Hospital), which was infused intravenously in 10 minutes, two hours after surgery and then eight-hourly for two doses, a total of $300 \mathrm{mEq}$ being given in the first 18 hours postoperatively. This rate of infusion was arrived at empirically, as the dangers of overrapid infusion are well known, and too slow a rate has no effect on acid-base balance.

Preoperative Assessment.-This was based on routine physical examination, history-taking, and chest radiographs. Tidal

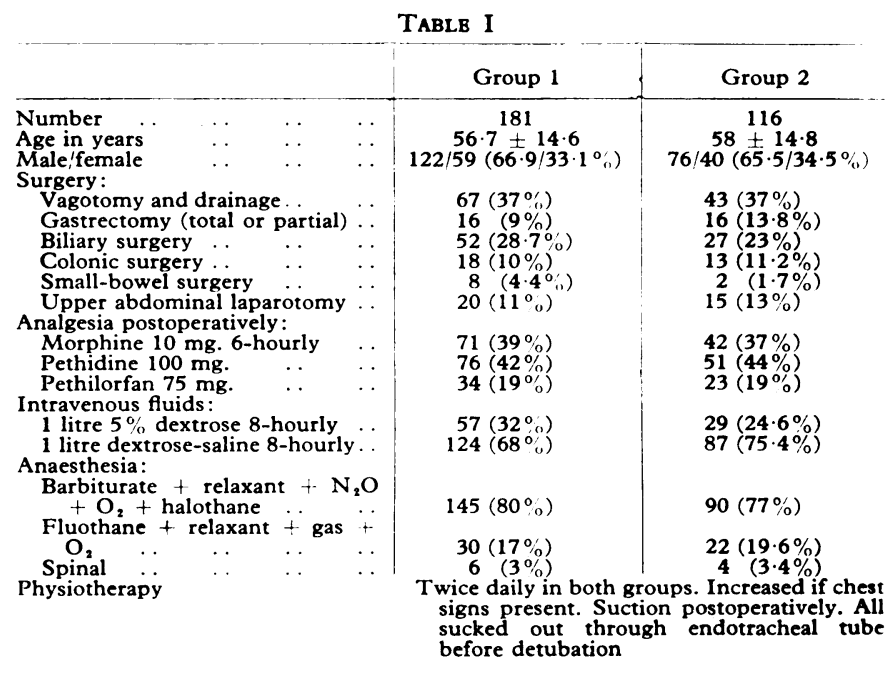


and minute volumes were measured, using a Wright respirometer and facemask, in the last 41 patients in each group before operation (Table II) and on the first and second postoperative days. Those patients in group 2 who were acidotic had tidal and minute volumes measured 30 minutes after the correction of the acidosis by intravenous bicarbonate. All these measurements were made by the same observer with the same instrument.

Chest Complications.- These were assessed as radiographic findings of atelectasis and collapse and consolidation, no classification being attempted. $X$-ray films were taken on the first and second postoperative days.

Blood Investigations.-In groups 1 and 2 the first 139 and 65 patients, respectively, had serum (venous) bicarbonate levels estimated preoperatively and on the first and second postoperative days-that is, about 24 and 48 hours after surgery. No patient had a temperature below $98.4^{\circ} \mathrm{F}$. $\left(36.9^{\circ} \mathrm{C}\right.$.) at the time of taking the sample. The last 41 patients in each group had blood gas analysis by Astrup technique (Astrup et al., 1960). Arterialized samples were taken from the dorsum of the hand by the technique of Paine et al. (1961).

\section{Results}

\section{Chest Complications}

In group 120 patients had temperatures of up to $100 \cdot 8^{\circ} \mathrm{F}$. $\left(38.8^{\circ} \mathrm{C}\right.$.), increased respiratory rate, and rhonchi on auscultation; no radiographic changes were noted in the first 48

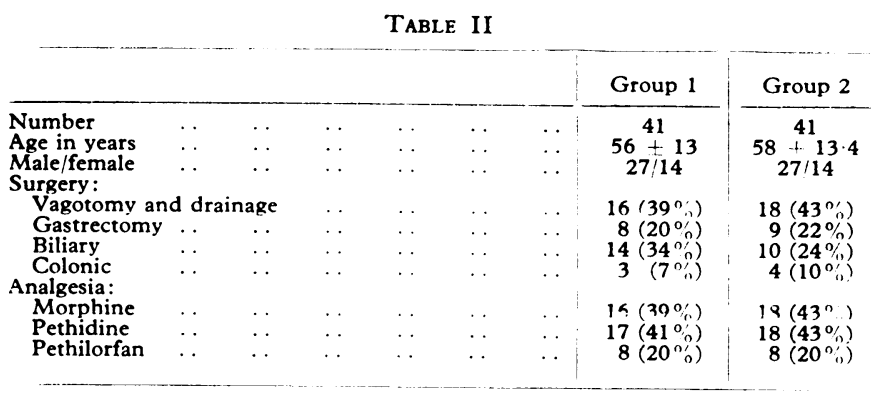

Barbiturate + fluothane + relaxant and $\mathrm{N}_{2} \mathrm{O}+\mathrm{O}_{2}$ anaesthesia for all

TABLE III.-Blood Results on First Day

\begin{tabular}{|c|c|c|c|c|}
\hline & \multicolumn{2}{|c|}{$\begin{array}{l}\text { Group } 1 \\
\text { Chest Complications }\end{array}$} & \multicolumn{2}{|c|}{$\begin{array}{c}\text { Group } 2 \\
\text { Chest Complications }\end{array}$} \\
\hline & Yes & No & No & Yes \\
\hline $\begin{array}{l}\text { Last } 41 \text { cases } \\
\mathrm{PCO}_{2}(\mathrm{~mm} . \mathrm{Hg}) \ldots \\
\mathrm{pH}_{\text {Base excess or }}\end{array}$ & $\begin{array}{c}27 \\
27 \cdot 6+0.58 \\
7 \cdot 43 \pm 0.006\end{array}$ & $\begin{array}{c}14 \\
34.0 \pm 0.81 \\
7.45 \div 0.005\end{array}$ & $\begin{array}{c}35 \\
35.1 \pm 0.42 \\
7.46 \pm 0.003\end{array}$ & $\begin{array}{c}6 \\
33 \cdot 3 \pm 1 \cdot 28 \\
7 \cdot 46 \pm 0.01\end{array}$ \\
\hline $\begin{array}{c}\text { deficit }(\mathrm{mEq} / 1 .) \\
\underset{(\mathrm{mEq} / \mathrm{l} .)}{\operatorname{Number}} \cdots\end{array} \mathrm{HCO}_{3}$ & $\begin{array}{c}-3 \cdot 86+0 \cdot 24 \\
116 \\
18 \cdot 3+1 \cdot 8\end{array}$ & $\begin{array}{c}0.54+0.56 \\
65 \\
25 \cdot 1+2 \cdot 4\end{array}$ & $\begin{array}{c}2 \cdot 12+0 \cdot 28 \\
101 \\
28 \cdot 4 \cdot 2 \cdot 8\end{array}$ & $\begin{array}{c}1 \cdot 70+0 \cdot 39 \\
15 \\
28 \cdot 1+3 \cdot 1\end{array}$ \\
\hline
\end{tabular}

TABLE IV.-Tidal and MinuteVolumes in Last 41 Patients in Each Group

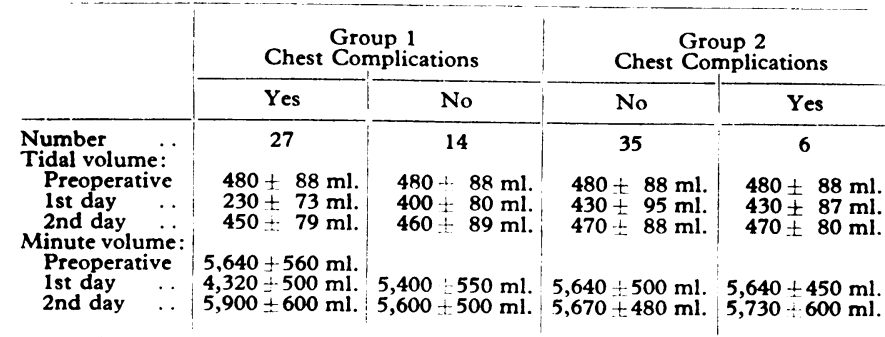
TABle V. Effect of Bicarbonate on Minute and Tidal Volumes of 27 Acidotic
Patients with Pulmonary Complications. First Day Results.

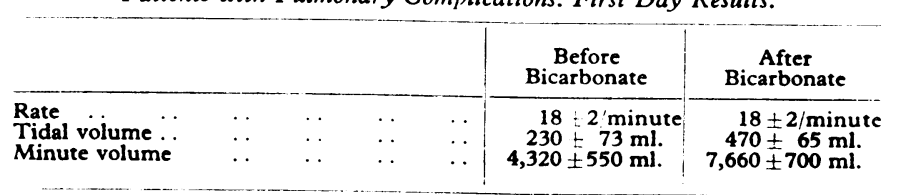

hours. Though changes did develop in four patients on the sixth postoperative day, these were not regarded as chest complications. Thus 116 patients $(64 \%)$ in group 1 had radiographic evidence of chest complications.

In group 2 seven patients had fever, increased respiratory rate, and rhonchi, but no sign of chest complications on radiographic examination during the first two days. Changes were noted in one patient on the fifth day, but again these were not regarded as chest complications. Thus 15 patients $(13.7 \%)$ in group 2 showing radiographic changes had chest complications. The $\chi^{2}$ test was applied to these figures and the difference was highly significant $(\mathrm{P}<0.001)$.

In the last 41 patients of both groups 1 and 2, who had blood gas analysis and respiratory volumes measured, the figures were $27(65.7 \%)$ and $6(14.5 \%)$ respectively. This again was highly significant.

\section{Blood Investigations}

Serum Venous Bicarbonate.-The average preoperative bicarbonate levels in the two groups were $25.3 \pm 3.1$ and $25.6 \pm 3.1 \mathrm{mEq}$ respectively. The difference in levels between those with chest complications and those without in group 1 was statistically significant by $t$ test (Table III).

Astrup Analysis. - These results show a metabolic acidosis in group 1, those patients with chest complications having a particularly pronounced acidosis. This difference was statistically significant. These patients had normal or near normal PCO: and acid-base levels by the second postoperative day, though all had had levels below the \pm 2.2 base range of normal; any marked base deficit was corrected by intravenous bicarbonate.

\section{Respirometer Results}

The tidal volume was quite significantly depressed $(P<0.001)$ in the 27 patients with chest complications in group 1, but not in the other patients in this group or group 2 (Table IV). Similarly, minute volumes were slightly depressed on the first postoperative day in the 27 patients in group 1 despite an increased respiratory rate. The tidal volume returned to normal, and the minute volume increased because the respiratory rate was unaffected after the administration of intravenous bicarbonate to these 27 patients (Table V). This very significant difference in the tidal and minute volumes was noted half an hour after the bicarbonate had been administered, the dose used being a corrective dose derived from the equation $0.3 \times$ body weight in $\mathrm{kg}$. $\times$ base deficit (Mellemgaard and Astrup, 1960).

\section{Discussion}

Metabolic acidosis tends to develop after surgery. Tissue damage, acidic intravenous infusions (including acid, citrate, dextrose, blood), anaesthetic agents (Price et al., 1966), and transient oliguria may all contribute to this effect. In this study I found a significantly greater degree of metabolic acidosis in patients who had a chest complication within the first postoperative day, the mean values of base excess in these patients with chest complications being significantly less than that in those patients without chest complications on the first postoperative day. Furthermore, in these patients with chest complications the "arterial" $\mathrm{PCO}_{2}$ was lower than in the patients without, yet their tidal and minute volumes of respiration were lower.

Without separate measurements of carbon dioxide production, one cannot be certain that this lower $\mathrm{PCO}_{2}$ reflects an increased alveolar ventilation. As this is very probable, however, I believe that the physiological dead space was reduced in the patients with chest complications, presumably in keeping with the collapse of lung areas which were no longer 
being ventilated. These changes were prevented by bicarbonate therapy, since there was no appreciable difference in type of surgery, postoperative analgesia, intravenous fluid therapy, or anaesthetic technique between the two groups. The incidence of postoperative radiological changes in the chest, however, was significantly reduced in group 2 . The improvement in acid-base balance in patients receiving bicarbonate therapy and the relative failure of these patients to increase both their alveolar ventilation and tidal and minute volumes, even in the presence of chest complications, indicated a considerable difference in gas exchange which cannot be fully explained without concomitant measurements of $\mathrm{CO}_{2}$ production. Simultaneous measurements of oxygen transfer by arterial $\mathrm{PO}_{2}$ and expired gas measurements may resolve the problem.

I would like to thank Mr. H. Shucksmith, Mr. L. LawsonLight, Mr. G. Wilson, and Mr. D. Pratt, consultant surgeons, for permission to investigate patients under their care. I also thank Dr. Alan Ness, Mr. G. G. Bird, Dr. J. Glanville, Dr. H. Herlinger, consultant radiologists; Mr. A. Powell, and the pathology depart- ment of St. James's Hospital, Leeds, Mr. M. P. Robinson, orthopaedic surgeon, Robert Jones and Agnes Hunt Hospital, Oswestry; and Dr. Susan L. Lewis for her help in preparing this paper.

\section{REFERENCES}

Astrup, P., Jorgensen, K., Andersen, O. S., and Engel, K. (1960). Lancet, 1,1035

Bendixen, H. H., Bullwinkel, B., Hedley-Whyte, J., and Laver, M. B (1964). Anesthesiology, 25, 297

Collins, C. D., Darke, C.. S., and Knowelden, J. (1968). British Medical Journal, 1, 401 .

Lewis, F. J., and Welch, J. A. (1965). Surgery, Gynecology and Obstetrics, 120,305 .

Mellemgaard, K., and Astrup, P. (1960). Scandinavian fournal of Clinica and Laboratory Investigation, $12,187$.

Ngai, S. H. (1967). In Modern Trends in Anaesthesia, ed. F. T. Evans and T. C. Gray, vol. 3, p. 184 . London, Butterworths.

Nunn, J. F., Coleman, A. J., Sachithanandan, T., Bergman, N. A., and Laws, J. W. (1965). British Fournal of Anaesthesia, 37, 3.

Paine, E. G., Boutwell, J. H., and Soloff, L. A. (1961). American Fournal of the Medical Sciences, 242, 431.

Palmer, K. N. V. (1955). Postgraduate Medical fournal, 31, 25.

Price, H. L., et al. (1966). Anesthesiology, 27, 24.

Prys-Roberts, C., et al. (1967). Lancet, 2, 399.

Stringer, P. (1947). Lancet, 1, 289.

\title{
Rhinoviraemia
}

\author{
G. E. D. URQUHART, ${ }^{*}$ M.B., M.R.C.PATH. ; E. J. STOTT, $†$ PH.D.
}

\begin{abstract}
ummary: Rhinoviruses have been isolated from the serum of two infants at necropsy. Failure to isolate viruses from ten other sera from infants who yielded rhinoviruses from their respiratory tracts suggests that true rhinoviraemia occurs rarely, and is infrequently associated with rhinovirus infections, both clinical and subclinical, and death. It is suggested that this is the first report of isolations of human rhinoviruses from the blood.
\end{abstract}

\section{Introduction}

A viraemic phase of infection has been shown or is presumed to occur in many virus infections. Rhinoviruses, though primary respiratory pathogens, are members of the picornavirus group, many members of which have been shown to have a viraemic phase. We report two cases of sudden unexpected death of infants from whose blood rhinovirus $\mathrm{H}$ strains were isolated.

\section{Case Reports}

Case 1.-A girl aged 3 weeks died in January 1968. There was no significant clinical history. The baby was taken into bed with its parents because it was crying .during the night. Next morning the mother awakened to find it lying upside down, face down under the blankets, and dead. At necropsy the lungs were grossly congested and oedematous, serous thoracic petechiae were numerous, and both adrenal medullae were haemorrhagic. The brain was macroscopically normal. Histological sections were not prepared. The cause of death was certified as asphyxia, but the indings were also consistent with acute anaphylaxis.

Case 2.-A girl aged 11 weeks died in November 1968 after a four-day history of "cold" with cough and diarrhoea. She was put to bed after feeding, being found dead in the cot next morning.

\footnotetext{
* Lecturer in Clinical Virology, Glasgow University Department of
Infectious Diseases, Ruchill Hospital, Glasgow N.W.

t M.R.C. Common Cold Research Unit, Harvard Hospital, Salisbury, Wilts.
}

At necropsy patchy lung congestion and scanty serous thoracic petechiae were found, the bowel contents were yellow and fluid, and the brain was congested. Some milky material-possibly aspirated stomach contents-was found in the trachea. The cause of death was certified as acute tracheobronchitis. As in Case 1, no histological sections were available for examination.

\section{Investigations}

Blood was collected post mortem by cardiac puncture in situ and multiple other specimens were taken with precautions to avoid cross-tissue contamination so far as possible. Specimen extracts, swabs, and blood fractions were stored at $-35^{\circ} \mathrm{C}$. between test procedures in the laboratory.

Rhinovirus isolation procedures were carried out in WI 38 and secondary monkey kidney tissue cultures incubated in conditions of reduced $\mathrm{pH}$ and rolled at $33^{\circ} \mathrm{C}$. At least two tissue culture passages were made before a negative result was accepted. All cytopathic agents isolated were shown to be acid-labile and chloroform-resistant; they failed to grow in WI 38 or monkey kidney tissue cultures incubated at $37^{\circ}$ and $33^{\circ} \mathrm{C}$ respectively. Acid lability, chloroform stability, and other laboratory procedures were performed as described by Grist et al. (1966).

Guinea-pig antisera were prepared by inoculating $1 \mathrm{ml}$. of virus (grown in WI 38 tissue culture to a titre of $10^{3.5} \mathrm{TCD}_{50} / 0.1 \mathrm{ml}$.) intraperitoneally, plus $2 \mathrm{ml}$. intramuscularly, with an equal volume of Freund's complete adjuvant, and bleeding out one week later.

\section{Virus isolations}

Rhinovirus $H$ strains were isolated initially from a tracheal swab taken from Case 1 and a nasal swab taken from Case 2. During a routine homologous neutralization test with serum from Case 2 it was noted that the tissue culture tubes inoculated with inactivated serum diluted $1 / 8$ as a toxicity control developed cytopathic effects similar to those of a rhinovirus. Tissue culture passage and physicochemical tests confirmed that these effects were due to a rhinovirus $H$ strain. Reisolation procedures on a fresh but uninactivated portion of this serum confirmed that a rhinovirus was present in the original specimen. 